\title{
Unpacking Attrition: A Change of Emphasis*
}

\section{JUNE CORMAN**, LYNN BARR', \& TULLIO CAPUTO ${ }^{\star}$}

\begin{abstract}
In this paper, we critique the conceptual, methodological and ideological issues involved in the university attrition debate in both Canada and the United States and discuss the salient policy implications of attrition research for higher education in Canada. We argue that American attrition research tends to result in policy recommendations aimed at those students who have already demonstrated their ability to succeed academically without assistance. A change of emphasis that places the question of attrition in the context of the role of higher education in society, particularly in relation to the issue of equality of opportunity, is suggested.
\end{abstract}

\section{Résumé}

Les auteurs analysent de façon critique les prémisses conceptuelles, méthodologiques et idéologiques qui sous-tendent le débat sur l'abandon scolaire au Canada et aux États-Unis. Ils évaluent les implications des recherches actuelles sur l'élaboration des politiques pour l'enseignement supérieur au Canada. Les auteurs soutiennent que les recherches américaines, en particulier, ont encouragé l'établissement de politiques correctives visant essentiellement les étudiants ayant démontré des aptitudes leur permettent de réussir sans soutien académique spécifique. Ils suggèrent de revoir le cadre de référence utilisé dans l'analyse des phénomènes liés à l'abandon et de développer des politiques correctives tenant compte du rôle social de l'enseignement supérieur, et plus particulièrement, du principe de l'égalité des chances.

* The authors wish to thank Stephen Richer, Katherine Kelly, Sid Gilbert, D. W.

Livingstone and the reviewers of Canadian Journal for Higher Education for their helpful comments and suggestions.

** June Corman is with the Department of of Sociology at Brock University

$\dagger$ Lynn Barr recently completed her Master's degree in Sociology at Carleton University.

$\Delta$ Tullio Caputo with the Department of Sociology and Anthropology at Carleton University, Ottawa. 


\section{Introduction}

There are a number of important policy issues facing Canadian institutions of higher education. In particular, questions concerning funding, enrolment, and accessibility have focused attention on student attrition from Canadian universities (Gibert \& Auger, 1987). The direction of student attrition research and its policy recommendations have serious implications for the future of higher education in Canada. In this paper we present a brief overview of both American and Canadian attrition research. The conceptual, methodological and ideological issues that form the basis of the attrition debate are examined. Salient policy implications of attrition research for higher education in Canada are also discussed. We argue that some American research on attrition emphasizes the retention of those students who have already demonstrated the propensity for academic success. Such an approach raises serious questions about the goals of higher education.

In assessing the relevancy of American research and policy for Canada, Canadian governments and universities must be sensitive to the strengths and weaknesses of the American research. Since the debate over the role of higher education in society is narrowly conceived in much American attrition research, serious questions about the role of higher education in society and the strategies adopted for responding to attrition are not raised. Several recent Canadian studies of university attrition have addressed some of the weaknesses in the American research. A number of serious policy considerations remain, however, and they are discussed at length in this paper.

\section{American Attrition Research}

Initial attempts to explain university attrition in North America were centred in the United States. Researchers in that country attempt to explain attrition by using complex theoretical models. For example, building on work by Spady (1970, 1971), Tinto (1975, pp. 94-97) argues that educational outcomes are the result of the degree of fit between the student and the university environment. According to Tinto, students enter university with a variety of pre-entry traits (such as family background, skills, high school performance) which are then related to the students' commitment to their career, educational goals and to post-secondary institutions. Pre-entry traits and commitments are then seen in this model as affecting the student's experience within the university. Specifically, the student becomes (or does not become) academically and socially integrated into the university setting. According to Tinto, the greater the 
social and academic integration, ceteris paribus, the greater the commitment to postsecondary education and the institution. This, in turn, enhances the students' likelihood of remaining at the institution.

Tinto's model has spawned numerous attempts at validation by other American researchers. Among these is work by Pascarella and Terenzini (1983) in which the salient constructs are operationalized to provide a test of the model in a residential setting. Total variance explained by the main effects model is modest and ranges from $19.1-21.7$ percent (1983, p. 219). Within this study, background characteristics and initial commitments explain little variance in persistence; their effect is indirect, being mediated through academic and social integration. Results tend to support the overall expectations of the model in that what happens to students after arrival at a residential university may be of importance to the departure/persistence decisions.

A test of the model by Pascarella et al. (1983) in a commuter setting produced results somewhat inconsistent with the residential test. Of particular interest is the fact that background characteristics are associated with a 9.9 percent increase in variance explained, while academic and social integration are associated with a 6.3 percent increase. A classification analysis based on background characteristics alone identified 19.1 percent of the persister and withdrawal groups. This suggests that background characteristics at commuter institutions may be more important predictors of attrition/persistence decisions than academic and social integration.

\section{Weaknesses in American Attrition Research}

Current attrition research in the American context suffers from three major weaknesses: (i) problems of conceptualization which include the failure to delineate clearly the categories of attrition, the failure to conceptualize adequately key concepts, such as academic integration, and the failure to critique sufficiently the match between the operational and conceptual definitions of key concepts (see Pascarella \& Terenzini, 1983); (ii) links between key variables in the attrition model, which are not adequately specified; and (iii) the ways in which students' experiences are shaped by institutional decisions are not sufficiently examined.'

The categories of the dependent variable, attrition, are not clearly delineated (Gilbert \& Auger, 1987). Although this weakness was recognized as early as the mid seventies (Tinto, 1975; Pantages \& Creedon, 1978), research in the 1980s neglected to make finer distinctions. The concept is typically defined as simply not returning to register in a second year. The modest amount of variance 
explained by the model may be the result of the failure fully to disaggregate the concept. One could argue that a different set of circumstances leads students to transfer to another university, as opposed to leaving the university system completely (Gilbert \& Auger, 1987). Different models may be required to explain the different forms of attrition (transfer to another institution, permanent withdrawal from the system of higher education, or temporary withdrawal) by different types of students in both residential and commuter settings (Gilbert \& Auger, 1987).

A second problem has to do with the point at which students decide to leave the university. It is unclear whether or not students who withdraw during their first year are included for analysis in American attrition studies. If they are not included, a potentially large body of withdrawals is unaccounted for. Based on the argument that voluntary withdrawal seems to be heaviest at the end of the Freshman year, much of the American research has focused on students who have voluntarily withdrawn from the institution at the end of the Freshman year (see for example Pascarella et al., 1983; Pascarella \& Terenzini, 1983).

Several American researchers fail to specify the timing of students' withdrawal decisions; that is, whether or not the withdrawal decision was made prior or subsequent to the completion of one full academic year. In cases where this key aspect (timing of withdrawal) is overlooked, the central variable to be explained has been inaccurately defined and studied. As a result, little is known about the processes leading to attrition before the end of the academic year.

While American researchers have made extensive attempts to expand upon the operational measures of academic and social integration, comparatively little effort has been given to the conceptualization of these terms. "Integration" is too diffuse a concept, leading researchers to confound attitudinal and behavioural dimensions. This diffuseness results in inconsistency of measures across studies. For example, in 1975, Tinto defined academic integration as the student's grade performance and his/her perception of intellectual development (1975, $\mathrm{p}$. 104). Subsequent researchers have operationalized academic integration to include, in addition: students' perception of faculty concern for quality classroom teaching and student development; frequency of Freshman year non-class contacts with faculty for academic purposes; hours studied per week; number of unassigned books read for pleasure; number of cultural events attended; honours program participation; peer conversations for academic purposes; and so on. Despite this proliferation of measures, little theoretical rationale is given which links these new measures to a conceptual definition of academic integration. 
Past research shows a relationship between background characteristics and a student's social and academic experience within the institution (Pascarella \& Terenzini, 1983). There is inadequate reporting, however, of the nature of the relationship between different components of the background characteristics and the student experience of social and academic integration. Later in this paper, we will discuss the important ramifications of this omission for American researchers' discussion of policy alternatives.

While the institutional experience of students is a central predictor variable in the model of attrition employed in American research, there are limited attempts by researchers to understand the ways in which students' experiences are shaped by institutional decisions regarding such factors as funding, campus structure and resource allocation. It must also be recognized that institutional decisions cannot be divorced from the broader political/economic context in which they are made. American researchers tend to measure the extent to which students integrate into the academic and social environment at a given institution. They do not, however, explain the nature of the academic and social environment the student confronts upon admission. Whether or not students integrate into the environment may be related to the structure and organization of the university they face upon admission. As Tinto (1987, p. 90) states: "It is unfortunate that...insights into the multiple effects of educational environments upon student behaviour have not been fully incorporated into the study of the process of student withdrawal." It is unknown whether or not different university environments produce different forms of integration. ${ }^{2}$

\section{Canadian Attrition Research}

Interest in studying attrition in Canada has expanded in the last decade (Gomme \& Gilbert, 1984; Gilbert \& Auger, 1987). Published research, however, remains comparatively scarce and Canadian research that is currently underway is heavily influenced by American attrition models. ${ }^{3}$ Work by Gilbert and Auger (1987) is a direct attempt to address several of the weaknesses found in American attrition research, particularly problems surrounding Tinto's (1975) model of attrition. Caution must be exercised in using American models and policy recommendations because American universities face a different set of problems than do Canadian institutions.

Attrition research in the United States currently coincides with a period in which many universities in that country face financial difficulties and find themselves in competition for a decreasing pool of potential students. Tinto (1987, p. 2) cites a predicted decline in total enrolment in higher education from 
12.2 million in 1984 to 10.5 million in 1995 . This prediction is especially disconcerting for small privately-funded institutions that "...have teetered on the brink of financial collapse" (Tinto, 1987, p. 2). College recruitment campaigns are not compensating for the drop in numbers. As a result, survival, especially for small institutions, hinges on student retention.

As of yet, Canadian institutions are not faced with declining enrolments, although future enrolment prospects are uncertain. Canadian universities currently face their own dilemmas, including increasing enrolments, decreasing financial resources and increasing concern for quality, efficiency and accountability. Skolnik and Rowen (1984) examine the growing concern with quality in terms of the "triangle" hypothesis. Those who accept this hypothesis argue that funding, quality, and accessibility exist in a relationship in which quality and accessibility compete for funding. The political and economic situation in Canada has serious implications for policy decisions in this area. These implications will be examined in greater detail later in this paper.

Additionally, some Canadian universities have a high proportion of students who may withdraw during the academic year, transfer to other institutions, or fail to return to the system of higher education. For example, at the University of Guelph, estimates show that only 62 per cent of first year students in fall 1986 re-registered in fall 1987 (Gilbert et al., 1989).

Gilbert (1989) takes into consideration the political and economic context facing institutions of higher education in Canada. He cites the decrease in public funding and the increase in the current pool of university applicants. This situation produces difficult policy decisions for Canadian universities. Provincial variation in systems of funding presents different alternatives to universities across the country. For example, funding packages in some provinces encourage universities either to expand their intake of applicants in order to retain a consistent level of public funding, or to limit (as some have) enrolment, in order to decrease their operating costs. How universities respond to fiscal restraint affects their structure and organization, and as a result affects the students' experience. Gilbert and Auger (1987) are also sensitive to the need to expand knowledge of external influences upon attrition. Of particular interest to them is the role of student finances in withdrawal decisions.

Also in contrast to American research, Canadian researchers such as Gilbert et al. pay particular attention to the need to disaggregate the dependent variable - attrition. Gilbert and Auger (1987) distinguish among varying types of withdrawal and are sensitive to the timing of various types of withdrawal (that is, during or after the academic year). Using discriminant analysis to investigate the factors which predict various departure categories, they found that the 
success of the independent variables in explaining withdrawal varies by type of departure.

\section{A Critique of Attrition Policy}

American researchers have recommended policy initiatives for specific institutions, directed toward improving student retention by increasing the levels of students' academic and social integration. Pascarella and Chapman (1983), for example, recommend that residential institutions sponsor programs, through student affairs offices, to enhance students' social and academic integration by increasing their involvement with peers and faculty. As well, they counsel institutions to increase the proportion of students living in residence, because of the strong positive relationship between residential living and integration.

Although Pascarella et al. (1983) found that background characteristics have a more direct influence on attrition at commuter institutions and that social integration has a negative impact on attrition, their policy recommendations are surprisingly similar for both residential and commuter institutions. Commuter institutions are encouraged to "...provide richer and more varied opportunities for satisfying social interaction and involvement...." (1983, p. 99).

Attrition researchers point to the importance of the institutional experience in affecting retention. They argue that pre-enrolment traits are less important to withdrawal decisions than are post-enrolment experiences (Pascarella \& Terenzini, 1983). Student retention/attrition then becomes the responsibility of the institution, and the institutional environment is targeted for manipulation. An analysis of the institutional environment, however, is not evident in the attrition research. Policy recommendations, therefore, fail to take into account the nature of institutional environments and variations in environments among institutions. Moreover, university administrators face varying constraints in their ability to manipulate the environment (location of the campus in the community, size of residences, availability of funds, classroom size and availability, availability of resources for special programs). This institutional variation must be taken into consideration when policy recommendations concerning the institutional experience are made.

Research at both residential and commuter institutions points to the importance of academic integration for persistence/withdrawal decisions. Included as an indicator of academic integration is the student's grade performance. Surprisingly, efforts to improve grade performance are not the major focus of policy recommendations. This may be a result of the fact that grade performance has not been found to be highly correlated with voluntary dropout 
decisions (Pascarella \& Terenzini, 1980, p. 68). It may also occur because academic dismissals are normally excluded from the research sample. The impact of grade performance may be masked by the failure of researchers to disaggregate categories of attrition. Gilbert et al. (1989, p. 13), in their analysis of the factors which could assist in the prediction of various student outcome categories, found that high school marks were useful to predict academic failure at university but not to predict voluntary withdrawal.

At this point it is important to specify the key questions asked in American attrition studies. Because many of the American attrition studies exclude academic dismissals from consideration, the concern seems to be to retain those students who achieve at least minimum academic standards during their first year (see Pascarella \& Terenzini, 1980; 1983). Terenzini (1982, p. 55) argues: "The issue before administrators, however, is not really how to retain students but, rather, how to retain those who can meet the academic requirements, would like to continue, and would benefit from an education at the institution." The same view is put forward by Tinto (1982, p. 697):

The proper question is not whether we can or should strive to reduce dropout; rather, one should ask for which types of students should specific policies be developed. Besides able persons of disadvantaged backgrounds, the proper object of our concern should be students who enter the institution with the skills, abilities, interests, and commitment to complete a given program of study. Among such students, one finds that they are more likely to withdraw voluntarily than fail academically and to transfer to another institution rather than leave higher education altogether.

American attrition researchers appear not to be interested in retaining students who do not meet the academic requirements of their first year programme, and therefore do not systematically examine the institutional experiences of these students. By ignoring the institutional experience of this group, researchers have no way of knowing the degree to which these experiences are similar to those of students who voluntarily withdraw after the first year.

Many American attrition researchers seem to be interested in retaining those students who can achieve the minimum grade point average on their own initiative. ${ }^{4}$ In fact, some researchers have gone so far as to recommend that institutions reduce student attrition by admitting students with the highest possible high school grade point averages (see Bean, 1980, p. 184). This could be a 
result of the fact that it is less costly to direct retention programs at individuals who achieve the minimum grade requirements rather than expending resources trying to improve the grade performance of students who do not meet the minimum academic standards on their own. In this way, resources need only be directed towards creating a more positive institutional experience for those who have demonstrated that they can succeed academically.

The implications of borrowing such policy directives for higher education in Canada merit attention. From the perspective of American attrition research, students who are unable to achieve the minimum academic standards are left to solve their own problems, while attention and resources are directed at those who are capable of surviving academically without assistance. The assumption underlying some Canadian admission policies is that the students accepted are capable of and prepared for obtaining a university degree. ${ }^{5}$ By not responding to the fact that there may be a relationship between preparedness and academic success, the university may foster the conditions leading to their academic failure.

The underlying goal of most American attrition research is to increase institutional retention. ${ }^{6}$ Pascarella and Terenzini (1980, p. 61), for example, are careful to point out that attrition research "...might have significant implications for decision makers concerned with alleviating the potentially wasted resources associated with attrition at their institutions." Similarly, Pantages and Creedon (1978, pp. 88-89) define the goal of attrition research as "...first to obtain as complete an understanding as possible, and then to apply this knowledge in designing programs aimed at lowering rates of attrition." Creating a positive institutional experience (either academically or socially) is seen as a means to retention rather than as a goal in itself. As Tinto $(1987$, p. 2$)$ indicates, some American "...institutions have come to view the retention of students to degree completion as the only reasonable course of action left to ensure their survival..." Any efforts directed towards improving the nature of the institutional experience seem to be a by-product of this primary goal.

Rather than address the issue of whom the system of higher education does or does not serve, policy directives stemming from American attrition research are aimed at retaining students at individual institutions. Researchers neglect to place the question of attrition in the context of the role of higher education in society. From a broader societal perspective, the issue ought to be who remains in the system of higher education, not who attends which institution. There is a large body of empirical research on this issue in Canada that could be incorporated into policy recommendations on attrition (Boyd et al., 1985). 
Attrition researchers in Canada recommend institutional intervention in the attrition problem at two points in time- prior to and subsequent to admission (Gilbert \& Auger, 1987; Gilbert \& Evers, 1989). First, they argue that high school grades, by themselves, are not a sufficient indicator for admission because grades do not reflect the range of skills and abilities that students may possess (Gilbert \& Evers, 1989). Instead, they recommend using a broader set of criteria to decide which students would have access to a university education. They include as criteria: “...combination, of reasoning, language skills and rank in high school class or other refined measures which clearly identify the group which would benefit from university and which would provide benefit to the broader society" (Gilbert \& Evers, 1989, p. 61). Policy makers also confronted the question of admission standards in the late 1950s and early 1960s when the number of university applicants out-paced the availability of places. The Atkinson studies (Fleming, 1959), undertaken at that time, failed to develop usable criteria to distinguish who was capable of completing university.

Second, they advocate a student development approach which would develop the talents of the total student population, not just a select group. They also recommend that "...those unsuited to higher learning do not continue, provided that distinguishing criteria involve performance factors (skill, interest, motivation, etc.) and not discriminatory mechanism [sic] based upon extra-educational characteristics (class, gender, ethnicity, etc.)." (Gilbert \& Auger, 1987, p. 20-21). Thus, although Canadian researchers lean towards Tinto's (1982) view that efforts should not be aimed at reducing attrition overall but rather at increasing the retention of certain types of students, they advocate more sensitive selection criteria.

Some of the policy recommendations outlined by Canadian researchers may prove difficult to initiate because specifying distinguishing criteria, other than high school grade performance, would prove to be complicated, time consuming and costly. Canadian researchers have also overlooked several factors in their recommendations for student selection, both upon admission and for participation in retention programs. While they take a position against using discriminatory criteria and practices (Gilbert \& Auger, 1987; Gilbert \& Evers, 1989), they still advocate a policy of promoting admission and retention programs for certain types of students. This creates problems for them because of the relationship between ascriptive and achieved characteristics. Class, race and gender are related to the distinguishing characteristics that Gilbert and Auger (1987) and Gilbert and Evers (1989) propose as selection criteria. For example, past research has shown a relationship between gender and the acquisition of 
skills, for example, girls do not typically enter university with a strong background in sciences and mathematics. Similarly, people of varying social backgrounds are differentially prepared to translate their cultural capital into academic success. This has been recognized in the Canadian research, since the model predicts a relationship between background characteristics (extra-educational criteria) and institutional commitment and social and academic experiences.

In their policy recommendations, Canadian researchers must consider the current fiscal constraints facing institutions of higher education and the impact of such constraints on students and universities. As outlined earlier, those who subscribe to what Skolnik and Rowen (1984) call the "triangle" thesis argue that funding, quality, and accessibility exist in a competitive relationship. Some critics challenge the usefulness of a policy of accessibility and argue that too much accessibility will have a negative effect on quality (see Gilbert \& Evers, 1989; Skolnik \& Rowen, 1984 for a further elaboration of this argument). The current situation of decreasing public funding in Canada has led some universities to increase the number of students admitted, in an attempt to offset declining finances. This has been accomplished through the admission of students with lower high school grade point averages. One potential result of this strategy is overcrowding, which could become a factor in producing an institutional environment that invites students to withdraw voluntarily.

Institutions do not use ascriptive characteristics as admission criteria. Canadian universities do not have affirmative action quotas. Students, however, are unequally prepared to succeed academically at university. In an atmosphere of scarce resources and overcrowding, many Canadian universities do not have adequate support for students who need supplemental help either academically or socially. The result of this strategy is that students are given access to the university system but are often left to their own devices upon arrival. The consequences of this strategy are harmful both for the individuals involved and society as a whole. Universities create a situation wherein students with inadequate preparation are not able to benefit to the same extent as others. This strategy may lead to an atmosphere that disadvantages particular groups of people in our society and which potentially may lead to a disproportionate rate of attrition among these groups. While in Canada we may espouse equality of opportunity through open admissions standards for higher education, we do not follow through by providing the conditions whereby people experience equal opportunity to benefit.

Canadian researchers must also be sensitive to the fact that the Canadian system of higher education consists primarily of commuter institutions. Finally, 
the relationship between classroom experiences and attrition should be explored. This may be especially important in commuter institutions where the students spend the bulk of their time on campus in the classroom.

\section{Conclusion}

Research on attrition raises a number of important policy questions about the role of higher education in society. American attrition research tends to employ a narrow, institutional definition of attrition. As a result, student retention becomes a technical question of how to manipulate existing institutional arrangements in order to retain those students who can meet the academic requirements of the institution.

While it is important to direct attention towards academic achievers, it is equally important to address the question of the role the system of higher education plays for various subgroups within society. A great deal of debate during the past few decades has centred precisely on this question. Critics of the educational system have repeatedly pointed out the consequences of the current educational system for the lower class, racial and ethnic minorities, and women. Much could be gained from applying the insights of researchers concerned with the role of higher education in society, to existing and future attrition research.

Particular attention should be given to the lived experience of various groups of students over the duration of their college or university attendance. This information could guide policy makers to a more effective use of resources aimed at providing a richer college or university experience for all students.

\section{Notes}

1 This discussion of the weaknesses in the American attrition literature pertains to both Tinto's model of attrition and to the research based upon the model. Certain weaknesses, however, are more easily attributed to either the model or to the research based upon the model.

${ }^{2}$ A useful starting point is the research done on educational climates of high schools by Ed McDill (1966).

${ }^{3}$ Given the paucity of published research concerning student withdrawal from Canadian universities, Pascal and Kanowitch (1979) conducted a study of unpublished withdrawal studies at Canadian universities.

4 A growing body of literature has emerged, however, that focuses directly on improving the first year experience inside and outside of the classroom (see, for example, the proceedings of The First Year Experience conferences hosted by The University of South Carolina including the first Canadian-American Conference held in 1988, and 
work by Gardner and Jewler, 1985). Programs that aim at easing the transition from high school to university are also in place at various Canadian institutions (such as the University 100 course in place at the University of Prince Edward Island and the Transitions programme operating at Carleton University).

5 Actually the range of preparedness of students entering some Canadian universities varies enormously: in 1990,14.1\% of students entering first year at Brock had an average of $\mathrm{C}$ on their O.C.A. credits while $23.3 \%$ had achieved an average of $\mathrm{A}$.

6 Tinto's (1987) work is a partial exception to this. In this work, he clearly states that a concern for the education of students and their social and intellectual development should be the long-term objective of institutional action $(1987$, p. 5). What is unclear in this work is whether or not Tinto supports this notion for all students admitted or only for those who have been determined by the institution as worthy of being educated (see Tinto, 1987, p. 135).

\section{References}

Bean, John P. (1980). Dropouts and turnover: The synthesis and test of a causal model of student attrition. Research in Higher Education, 12 (2), 155-187.

Boyd, Monica, et al. (1985). Ascription and achievement: Studies in mobility and status attainment in Canada. Ottawa: Carleton University Press.

Fleming, E.L. (1959). Atkinson study of utilization of student resources, Report 5: Personal and academic factors as predictors of first year success in Ontario universities. Toronto: Ontario Institute for Studies in Education.

Gilbert, S.N. (1989). The forgotten purpose and future promise of university education. Canadian Journal of Community Mental Health, 8(2), 103-122.

Gilbert, S.N., \& Auger, M. (1987). Admission and attrition: Preliminary results of the CEASE project on university attrition. Paper prepared for the Canadian Society for the Study of Higher Education.

Gilbert, S.N., \& Evers, F. (1989). Accessibility and quality in higher education. The Service Industries Journal, 9(4), 44-62.

Gilbert, S.N., Evers, F., \& Auger, M. (1989). University attrition differentiated: Rates and institutional influences. Prepared for the C.S.S.H.E. Meetings, Laval University.

Gomme, I., \& Gilbert, S. (1984). Paying the cost: Some observations on the problem of postsecondary student attrition. The Canadian Journal of Higher Education, 14 (3), 95-100.

McDill, E. (1966). Sources of educational climates in high schools. Baltimore, Md.: John Hopkins University.

Pantages, T., \& Creedon, S. (1978). Studies of college attrition: 1950-1975. Review of Educational Research, 48 (1), 49-101.

Pascal, Charles E., \& Kanowitch, Seymour. (1979). Student withdrawals from Canadian universities: A study of studies. Toronto: Ontario Institute for Studies in Education. 
Pascarella, E., \& Chapman, D. (1983). Validation of a theoretical model of college withdrawal: Interaction effects in a multi-institutional sample. Research in Higher Education, 19 (1), 25-48.

Pascarella, E., Duby, P., \& Iverson, B. (1983). A test and reconceptualization of a theoretical model of college withdrawal in a commuter institution setting. Sociology of Education, 56 (2), 88-100.

Pascarella, E., \& Terenzini, P. (1980). Predicting freshman persistence and voluntary dropout decisions from a theoretical model. Journal of Higher Education, 51 (1), 60-75.

Pascarella, E., \& Terenzini, P. (1983). Predicting voluntary freshman year persistence-withdrawal behavior in a residential university: A path analytic validation of Tinto's model. Journal of Educational Psychology, 75, 215-226.

Skolnik, M., \& Rowen, N. (1984). Please, sir, I want some more: Canadian universities and financial restraint. Toronto: Ontario Institute for Studies in Education.

Spady, W. (1971). Dropouts from higher education: Toward an empirical model. Interchange, 2 (3), 38-62.

Spady, W. (1970). Dropouts from higher education: An interdisciplinary review and synthesis. Interchange, 1 (1), 109-121.

Terenzini, P. (1982). Designing attrition studies. In Ernest T. Pascarella (ed.) Studying student attrition. San Francisco: Jossey-Bass Inc.

Tinto, V. (1987). Leaving college: Rethinking the causes and cures of student attrition. Chicago: The University of Chicago Press.

Tinto, V. (1982). Limits of theory and practice in student attrition. Journal of Higher Education, 6 (6), 687-700.

Tinto, V. (1975). Dropouts from higher education: A theoretical synthesis of recent research. Review of Educational Research, 45 (1), 89-125. 